\title{
The Role of Policies in Supporting the Diffusion of Solar Photovoltaic Systems: Experiences with Ontario, Canada's Renewable Energy Standard Offer Program
}

\author{
Chris Adachi * and Ian H. Rowlands \\ Department of Environment and Resource Studies, University of Waterloo, 200 University Avenue \\ West, Waterloo, ON, N2L 3G1, Canada; E-Mail: irowland@uwaterloo.ca \\ * Author to whom correspondence should be addressed; E-Mail: chris.adachi@ gmail.com; \\ Tel.: +1-519-888-4567, Ext. 32574; Fax: +1-519-746-0292.
}

Received: 10 November 2009 / Accepted: 22 December 2009 / Published: 24 December 2009

\begin{abstract}
Traditionally, high initial capital costs and lengthy payback periods have been identified as the most significant barriers that limit the diffusion of solar photovoltaic (PV) systems. In November, 2006, the Ontario Power Authority (OPA) introduced the Renewable Energy Standard Offer Program (RESOP), offering owners of solar PV systems with a generation capacity under $10 \mathrm{MW}$ a 20 year contract to sell electricity back to the grid at a guaranteed rate of CAD $\$ 0.42 / \mathrm{kWh}$. While it is the intent of incentive programs such as the RESOP to begin to lower financial barriers in order to increase the uptake of solar PV systems, there is no guarantee that the level of participation will in fact rise. The "on-the-ground" manner in which consumers interact with such an incentive program ultimately determines its effectiveness. This paper analyzes the relationship between the RESOP and solar PV system consumers. Experiences of current RESOP participants are presented, wherein the factors that are either hindering or promoting utilization of the RESOP and the adoption of solar PV systems are identified.
\end{abstract}

Keywords: solar; energy; photovoltaics; policy; renewable energy; diffusion; Ontario; electricity; Canada 


\section{Introduction}

As awareness and concern over climate change continue to increase at the outset of the 21 st century, attention has turned to finding solutions focused largely on carbon and energy sustainability. One strategy has been to turn to renewable energy resources. It has been argued that a transition to an electricity supply mix comprised of electricity generation from renewable energy technologies (RETs) and sources will require policies to facilitate their uptake [1-3]. Strategies such as Feed-In Tariffs (FITs) and Renewable Portfolio Standards (RPSs) have been employed to improve the diffusion of renewable energy technologies [4]. The creation of a policy, however, does not necessarily result in the uptake of RETs; in other words, policies do not necessarily unlock financial resources for potential investors. While a well designed policy selection process is necessary, the implementation and effectiveness of an economic instrument is of equal importance.

Much reflection has taken place on strategies such as FITs and RPSs, though focus has been primarily on financial barriers, and experiences have been drawn predominately from European cases. To date, relatively little reflection has been undertaken with respect to the influence of North American policies on RET feasibility. The purpose of this article will be to describe the drivers and barriers to the adoption of a specific RET, residential roof-top solar PV systems, in the presence of the first financial incentive program of its kind in North America, the Renewable Energy Standard Offer Program (RESOP).

Though it is the intent of incentive programs such as the RESOP to begin to lower financial barriers and increase the affordability of solar PV systems, there is no guarantee that their presence will result in a rise in adoption. The "on-the-ground" manner in which consumers interact with such incentive programs ultimately determines their effectiveness. Due to the complex nature of technological diffusion, there is a need to broaden the analysis to understand the full suite of drivers and barriers in the North American context.

\section{Drivers and Barriers to Solar PV System Diffusion}

To improve the diffusion of renewable energy technologies, it has been argued that we must better understand the factors that are inhibiting adoption [5,6]. A plethora of barriers to the diffusion of solar PV systems have been identified in the literature [7]. Amongst them, high initial capital costs and lengthy payback periods are most often cited as the primary barriers to diffusion and are supported by evidence from the United States, Spain, Germany, and the United Kingdom [5,8-11].

While economic challenges are those most often cited, it should be noted that other hypotheses have been posited to explain the slow diffusion of solar PV systems. Del Rio and Unruh have argued that "proximate causes, like differential costs of the two technologies or available resources, provide only limited explanatory power" [9], suggesting that institutional factors may play a decisive role in the diffusion process. Jacobsson and Johnson state that "networks and institutions are also constituent parts of a technological system and influence, therefore, the processes of discovery and selection" [10]. Further supporting this line of argument is Liberatore [12], who warns of the dangers of a process design that fails to adequately account for institutional capacity. Policies may fail when assumptions that local administrations are adequately funded and staffed with specialized personnel prove to be 
false. In these cases, Liberatore argues that "if no explicit and careful consideration is paid to the actual working of institutions..., the formulation and implementation of any kind of policy instrument will be based on rather unsteady ground" [13].

Still, economic and institutional factors constitute only a portion of a plethora of factors which may influence the diffusion of solar PV systems. Given that the presence of specific factors appears to be context dependent at this time, there is reason to hypothesize that other types of factors may influence the uptake of said systems. An exploration of the case of solar PV system adoption and a financial policy in Ontario has thus been undertaken to shed further light on this topic.

\section{Empirical Study of the Renewable Energy Standard Offer Program and the Diffusion of Solar PV Systems in Ontario, Canada}

\subsection{The Ontario Electricity System}

Traditionally in Canada, provinces have had the exclusive right to make laws in relation to the "development, conservation and management of sites and facilities in the province for the generation and production of electrical energy" [13]. As a result, individual provinces have taken the lead in determining the fate of their respective electricity systems. In Ontario - the country's largest province, with a population of 13 million inhabitants - electricity has historically been provided by public organizations in a (largely) vertically-integrated manner. Most generators are owned by the provincial government (through Ontario Power Generation), and the majority of the transmission network is managed by Hydro One, another provincially-owned entity. At the municipal level, electricity is delivered to customers in urban areas by locally-owned (often public) 'local distribution companies' (or LDCs); in many rural areas, Hydro One serves as the distributor. While customers have the option to source their electricity from any of a variety of power companies (including so-called 'energy marketers'), LDCs are obliged to manage the local delivery of electricity, regulated by the Ontario Energy Board.

Electricity is generated by a variety of means in Ontario. In 2008, the province's 159.3 TWh were generated largely by nuclear power stations (53\% of all generation), hydroelectric dams (24\%), coal-fired power stations (14.5\%), other power stations (largely natural gas, excluding wind) (7\%) and wind turbines $(1 \%)[14]$.

The Government of Ontario has been publicly committed to increasing the sustainability of the province's electricity supply system. Before coming to power in 2003, the Liberal party (while in opposition), called for the early closing of the province's coal-fired power stations - originally setting a shut-down date of 2007. After coming to power, and after establishing the Ontario Power Authority, it continued to push for sustainability considerations in electricity planning. This took not only the form of a variety of conservation and demand management programs and targets, but also ambitions to increase the share of renewable resources in electricity supply (see, for example, [15]). While not without its critics - many claiming that the reality did not live up to the claims - it is nevertheless the case that the Province was one of the first in North America to enact a variation of a 'feed-in tariff'. Announced in March 2006, stakeholder negotiations followed, and the program itself was launched in November 2006. 
Figure 1. The Ontario Electricity System. Source: Ontario Power Authority, http://powerauthority.on.ca/Page.asp?PageID=376\&ContentID=817\&SiteNodeID=118\&B L_ExpandID=/.

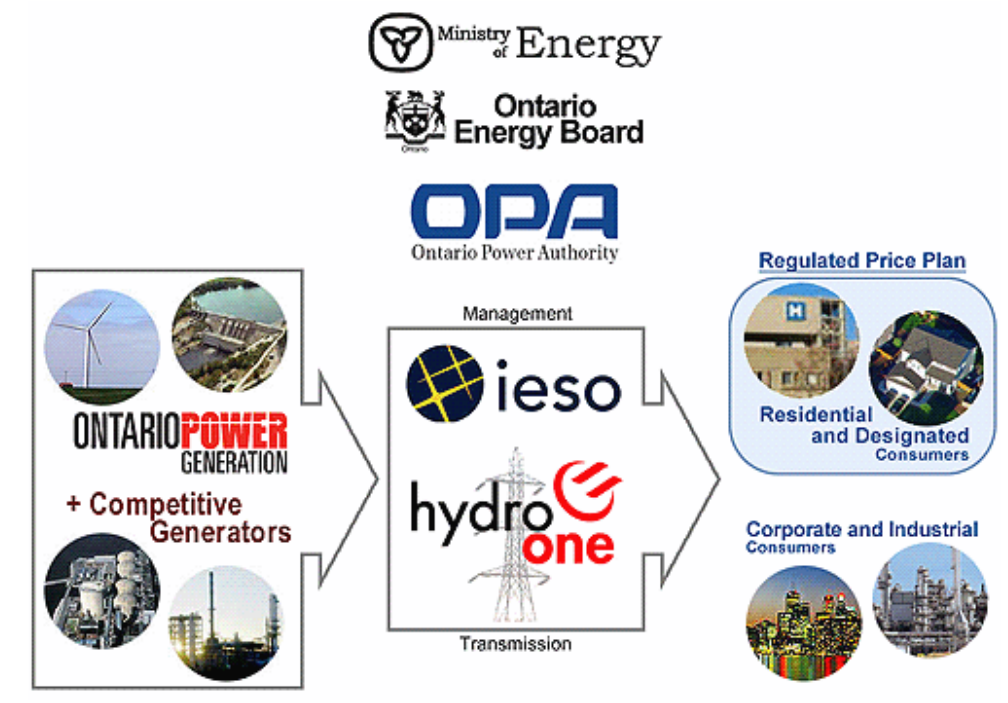

\subsection{The Renewable Energy Standard Offer Program}

Since 2006, two programs have been implemented in Ontario, Canada, to compensate generators of electricity from a renewable energy source. In early 2006, the Ontario government introduced its Net-Metering Program, wherein which generated electricity is used to meet the demands of the consumer/generator. When generation exceeds consumption, surplus electricity is exported to the grid. Customers pay the "net" difference between their electricity consumption and export- thereby selling electricity under the same rate structure from which they are purchasing it from the grid [16].

In late 2006, the Renewable Energy Standard Offer Program was created, presenting a different approach to financial compensation. As opposed to directly consuming the electricity generated by a renewable energy source, consumers sell all of the electricity they generate directly to the grid [17]. The intent of the RESOP, as stated by the Ontario Power Authority, is "to help Ontario meet its renewable energy supply targets by providing a standard pricing regime and simplified eligibility, contracting and other rules for small renewable energy electricity generating projects" [15].

The RESOP provides a generator of electricity from a renewable resource a 20 year contract, during which "solar PV generators are compensated at a fixed rate of 42.0 cents per $k W h$ " [17]. The formal agreement between the OPA and the consumer is called a Standard Offer Contract (SOC). To obtain a SOC, a generator must complete an online application and meet a number of planning requirements for eligibility. For example, it is the responsibility of the consumer to ensure that they are properly connected to the grid in Ontario. The consumer is also solely responsible for establishing their metering requirements and coordinating their metering configuration with their local distribution company, as well as for all connection and metering costs [17].

As of the December, 2008 RESOP Progress Report, 290 contracts had been executed for solar PV projects, 121 of which were in commercial operation. Of the 121 projects in commercial 
operation, 120 were at the scale of microgeneration $(<10 \mathrm{~kW})$, and had a cumulative generation capacity of $617 \mathrm{~kW}$ [18]. Our goal was to speak with as many of those within this sample who had acquired a SOC and who were either complete with or close to completing the installation and grid connection process of a residentially mounted solar PV system; targeting such a population would allow us to understand better the drivers and barriers for early adopters.

\section{Research Design}

The acquisition of data occurred through interviews with households of the Ontario population who had executed a Standard Offer Contract for a rooftop solar PV system less than $10 \mathrm{~kW}$ in size and who had either entirely completed the adoption process and were receiving financial compensation through the RESOP or who were in the process of doing so. The target population at the time of recruitment (November, 2008) was 105 households. Seventy-three candidates were selected for recruitment based on the ability to retrieve contact information from public online databases. Interview candidates were contacted by mail; candidates who did not respond to the mailed invitation for participation were then contacted by telephone with the intent of improving response rates. Twenty-four households ultimately agreed to an interview. Figure 2 provides full details.

Figure 2. Sampling Frame Composition.

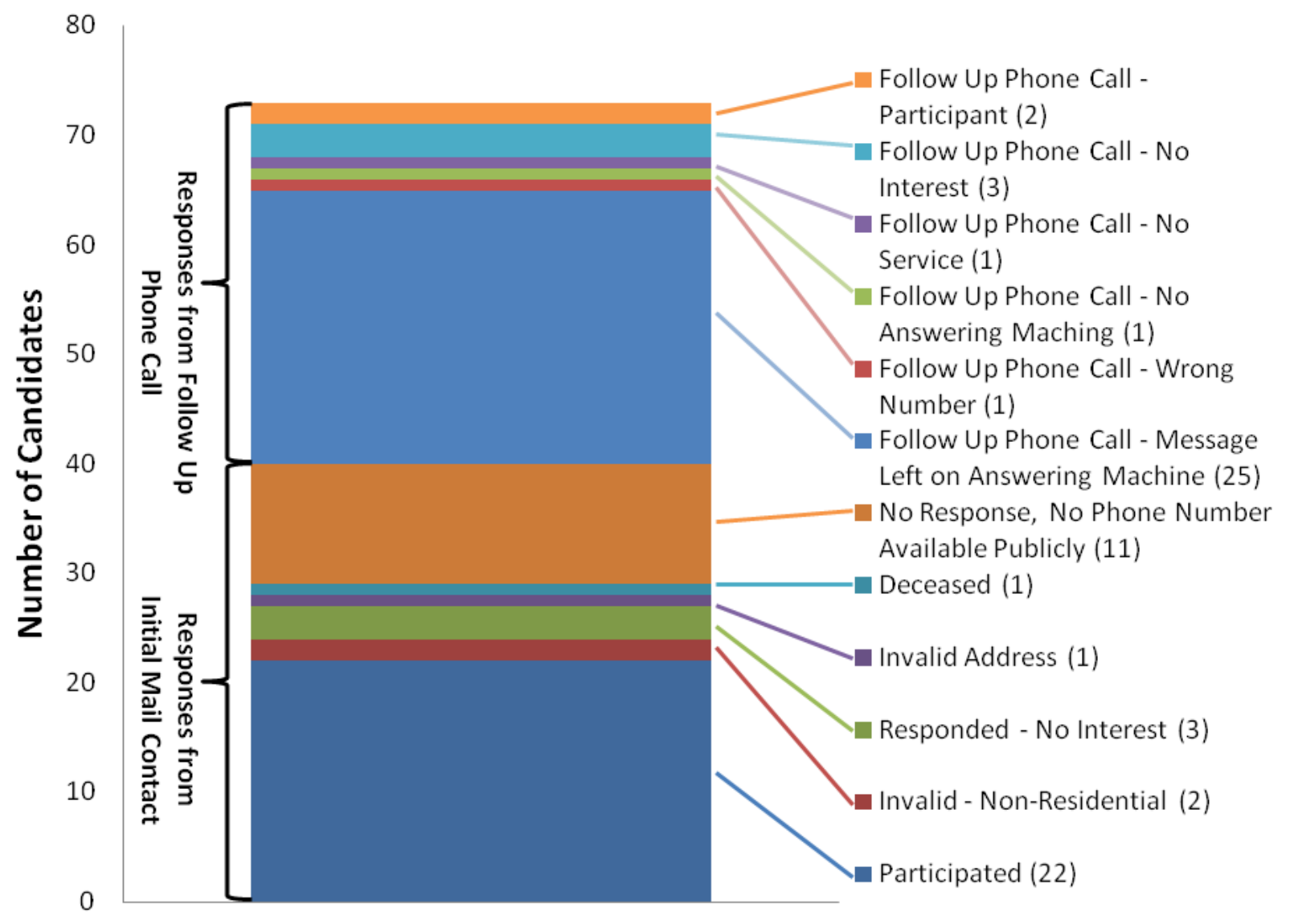

Sampling Frame Composition 
Interviews were conducted between November 19, 2008 and December 5, 2008; they ranged in length from 19 to 55 minutes and had an average length of 33 minutes. Interviews were of a semistructured nature, utilizing open-ended questions and probes to acquire the information desired. To collect data, interviews were audio recorded. Ten interviews took place in person, nine at the residence of the participant(s) and one at a diner near a participant's residence; 14 took place over the telephone.

One noteworthy limitation to this study design is that the data from which the findings are drawn shed light solely onto the experiences of consumers who have adopted solar PV systems, without identifying why people did not adopt. This would yield interesting findings potentially.

Furthermore, based on this sample, findings cannot be generalized to the entire target population, nor can they be expanded to the greater provincial population. A sample of 24 participants out of a target population of 105 is insufficient to extrapolate representativeness to said population. Even if this sample had been representative, results could not be expanded to apply to the general population since those members of the target population can most likely be characterized as early adopters, and thus will tend to have different behavioural, attitudinal, and demographic characteristics than later adopters [19]. Therefore, one should be cautious not to generalize results.

\section{Results}

The results reveal that there are three key stages associated with the adoption of a solar PV system in Ontario: (i) the decision to adopt, (ii) the process of adopting, and (iii) the continued generation of solar PV electricity and participation in the RESOP. In other words, to actually have renewable solar 'electrons feed into the grid', and thus displace less sustainable means of generating electricity, these three stages have to be successfully navigated. All three stages were successfully completed by our 24 participants (it would be interesting to know more about those who 'fell by the wayside' somewhere on this journey; that is not part of this research but that it is certainly worthy of future research). In this section, we identify the drivers and barriers experienced at each of these stages.

\subsection{Stage 1: The Decision to Proceed-Why Households Adopt Solar PV Systems}

Three factors, one driver, one barrier, and one key catalyst, have emerged from this study's sample as being of prominence to the decision to adopt a solar PV system: (i) sustainability, (ii) money and the RESOP, and (iii) cooperative purchasing groups, respectively.

\subsubsection{Sustainability}

Sustainability related concerns were identified by all 24 participants. Thirteen participants explicitly identified sustainability as the primary factor influencing their decision, while another eight noted that sustainability was a prominent influence on their decision. The remaining three participants, while addressing the role of sustainability, lent no explicit weighting to the influence of sustainability. Compared to any other identified factor, sustainability emerged as the primary driver for the adoption of a solar PV system. Specific factors identified included (with respondent frequencies in parentheses): 
concerns over pollution (20), climate change (4), energy concerns-specifically oil and gas (5), air quality (1), and the health and well-being of future generations (5).

\subsubsection{Money and the RESOP}

Seventeen of 24 participants noted that the high initial capital cost of the solar PV systems, coupled with the lengthy financial payback period, was the primary barrier they encountered in their decision to adopt. Of the 24 participants, ten purchased and installed their solar PV systems prior to their knowledge of the creation and implementation of the RESOP, demonstrating that the RESOP had no influence over their original decision. Of the remaining 14 participants, seven stated that they would have purchased a solar PV system even in the absence of the RESOP, while one participant suggested that they were unsure whether or not they would have purchased. The remaining six participants noted that they would not have purchased a solar PV system had the RESOP not been present, five of whom noted that the RESOP was the catalyst for their action. (As with any form of social research, the validity of participant responses is threatened by question bias, poor recall, and reflexivity. While all three concerns were considered and addressed in this research's methods design, one should nonetheless remain aware of their threat to data validity). Therefore, the RESOP can be said to have played a definitive role in influencing six consumers $(25 \%)$ to adopt, with the potential of a seventh adopter.

\subsubsection{Cooperative Purchasing Groups}

Over the past decade, a number of community-based cooperative purchasing groups (CPG) have emerged throughout the province of Ontario. Aside from their common concerns over energy sustainability and climate change, these groups have been formed with the intent of facilitating a bulk purchase of solar PV systems at a discounted rate. Most groups begin by holding public meetings wherein public interest is gauged. For example, after a few public meetings, one such group had over 300 signatures demonstrating interest in purchasing a solar PV system or a solar water-heater (because the cooperative purchasing group, at the time of its initial meetings, was attempting to organize purchases for both solar PV systems and solar water heaters, the 300 signatures were related to both technologies, and not simply solar PV systems). CPGs then tender bids to solar PV system venders for the purpose of creating a competitive bidding process across vendors and getting a "bulk purchase deal". From this process, an optimal balance is found for the purchasers between pricing and the quality of product and service.

CPGs were influential in their enabling of consumers to proceed from motivations to action. With respect to the use of a CPG, of the 11 participants who utilized their services, nine identified their CPG as the catalyst for their adoption, suggesting that they would not have adopted in the absence of a CPG. CPGs ultimately served as brain centers, wherein 'expertise' could be passed on to consumers by organizing members in a simplified and tangible manner. By joining a CPG, members interested in purchasing a solar PV system could become better educated about the technology and its associated installation and configuration complexities. Shared experiences could also be communicated amongst 
purchasers and organizing members. Such a process served to quell the concerns of potential consumers, such as a misunderstanding of the technology (e.g., system reliability).

\subsection{Stage 2: Drivers and Barriers to the Adoption Process}

Thus far, the results presented have addressed the factors influential in the original decision to adopt a solar PV system. Upon making the decision to adopt, however, the majority of study participants demonstrated little awareness and/or understanding of the processes required to install a solar PV system, connect it to the electricity grid, and to secure a contract through the province in order to receive payment for the electricity they were selling to the grid. This lack of understanding is reflected in the difference between the factors influencing the original decision to adopt (prior to the adoption process), and those that arose during the actual adoption experiences of consumers.

The adoption process consisted of three phases: the purchase and installation of a solar PV system (Phase I), the connection of the solar PV system to the electricity grid (Phase II), and the acquisition of a SOC in order to receive financial remuneration from the province (Phase III). These phases are presented in Figure 3.

Figure 3. The Three Phases of the Adoption Process Stage.

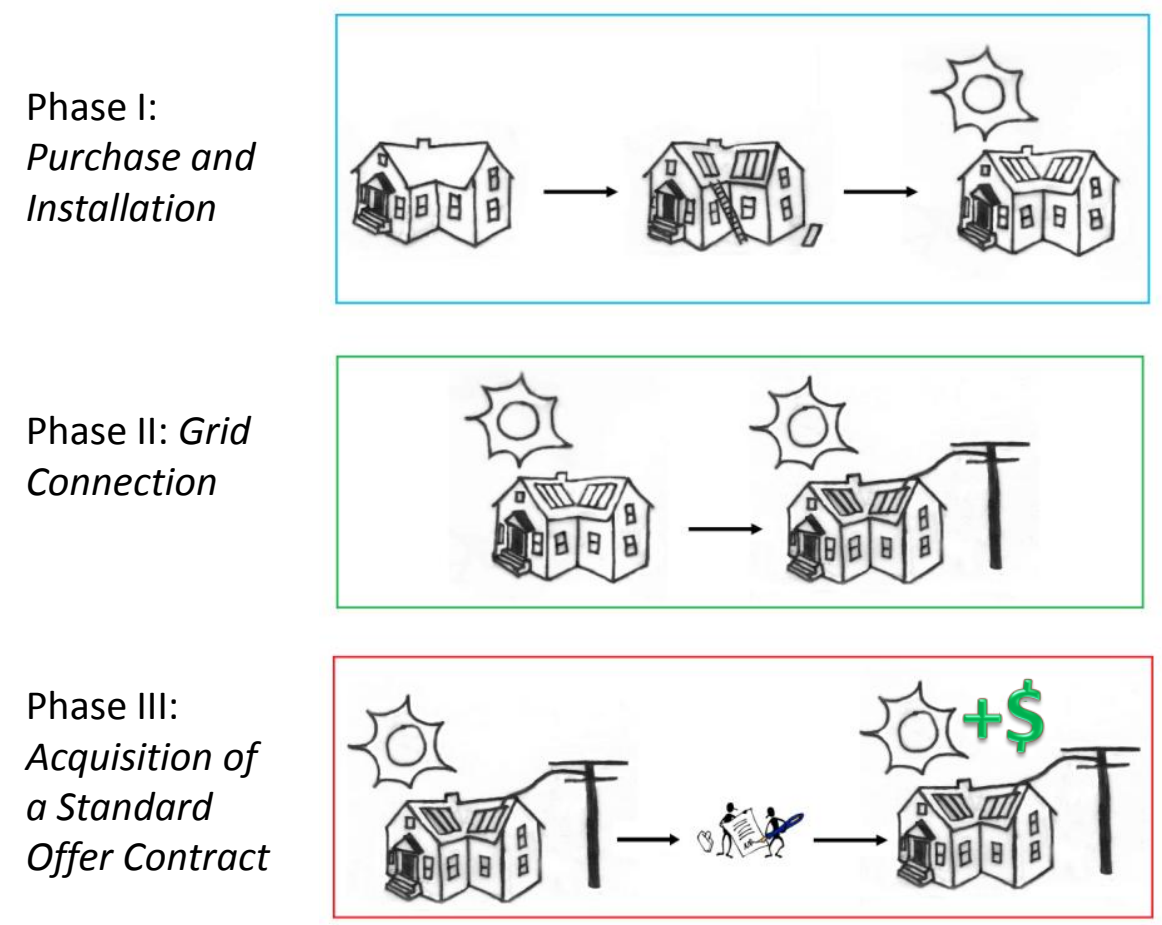

Across the three adoption phases, participant experiences revealed that the grid connection process was the most troublesome, followed by the acquisition of a SOC through the RESOP application process (Figure 4). It should be noted that these experiences were distributed across multiple LDCs and vendors. Six different vendors (for the purchase of the PV equipment) were used by the 24 participants. Participants were distributed geographically across the province, falling under the jurisdiction of nine different LDCs. 
Figure 4. Impressions of the Adoption Process Stage Phases.

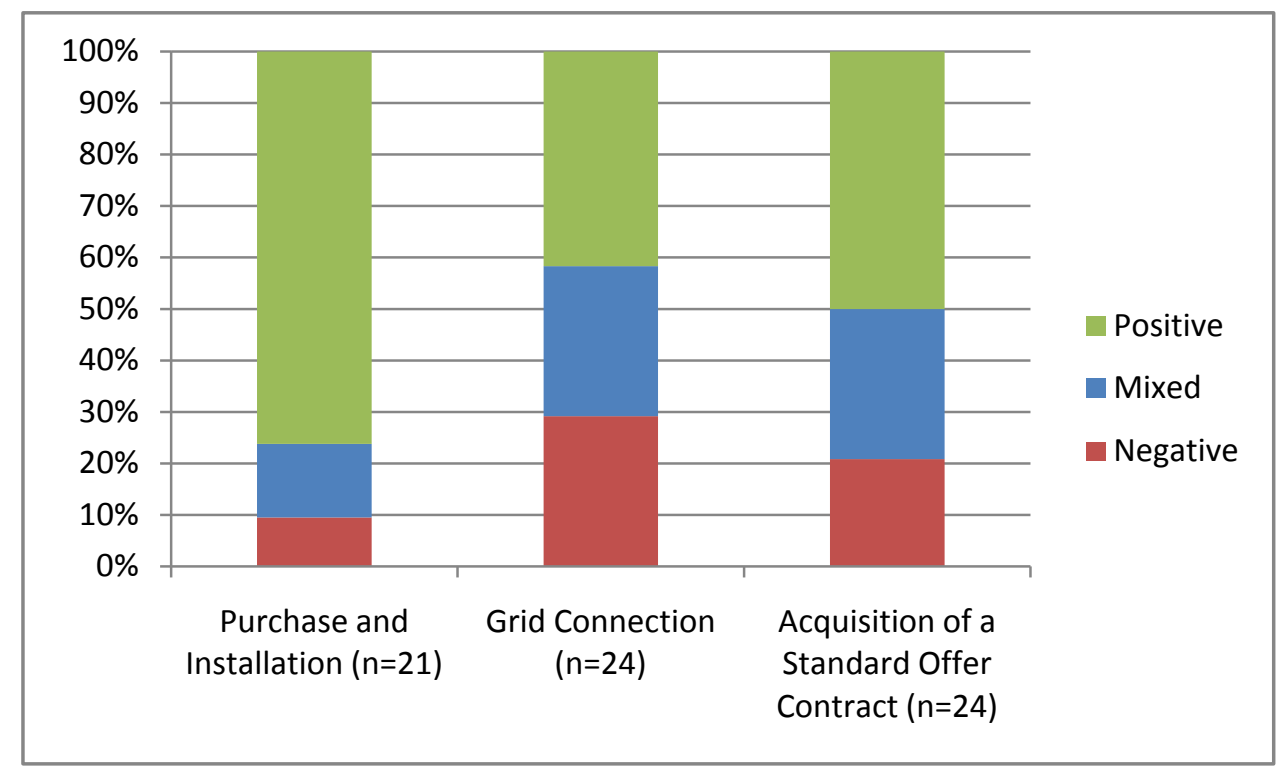

Table 1. Sample Quotations of the Adoption Process Stage Phases.

\begin{tabular}{|c|c|c|c|}
\hline & $\begin{array}{l}\text { Purchase and } \\
\text { Installation: }\end{array}$ & Grid Connection: & Acquisition of a SOC: \\
\hline $\begin{array}{l}\text { Positive } \\
\text { Experiences }\end{array}$ & $\begin{array}{l}\text { "They ... did a } \\
\text { really fantastic, } \\
\text { professional, clean, } \\
\text { safe worksite." }\end{array}$ & $\begin{array}{l}\text { "Getting them to actually come out, it } \\
\text { was actually pretty good } \\
\text { communication. In general, it was } \\
\text { good." }\end{array}$ & $\begin{array}{l}\text { "The OPA ... they were pretty } \\
\text { good." }\end{array}$ \\
\hline $\begin{array}{l}\text { Mixed } \\
\text { Experiences }\end{array}$ & $\begin{array}{l}\text { "Since we were so } \\
\text { early, I don't think } \\
\text { they even knew } \\
\text { what they were } \\
\text { doing." }\end{array}$ & $\begin{array}{l}\text { "When [LDC] came online with this, } \\
\text { everything was ok. But, for like } 6 \\
\text { months, they didn't know what to do." }\end{array}$ & $\begin{array}{l}\text { "It wasn't that it was bad, because } \\
\text { [retailer] gave me a whole outline } \\
\text { on what to fill out ... everything's } \\
\text { on a timeframe. That's what kinda } \\
\text { bugged me ... a lot of paperwork." }\end{array}$ \\
\hline $\begin{array}{l}\text { Negative } \\
\text { Experiences }\end{array}$ & $\begin{array}{l}\text { "... it's the } \\
\text { installer. My } \\
\text { installer really } \\
\text { screwed up." }\end{array}$ & $\begin{array}{l}\text { "The BS that we got from [LDC] ... that } \\
\text { was a real hassle. I left that with } \\
\text { [installer]. If it had been up to me, I } \\
\text { woulda washed my hands and walked } \\
\text { away ... I've heard other nightmare } \\
\text { stories about them." }\end{array}$ & $\begin{array}{l}\text { "I ended up reading the } \\
\text { instructions for hours and hours } \\
\text { and hours ... It was really just a } \\
\text { case of bullshit. If the instructions } \\
\text { were decent and all the people had } \\
\text { their act together, it should be just } \\
\text { a Saturday afternoon of work." }\end{array}$ \\
\hline
\end{tabular}

4.2.1. Phase I: Purchase and Installation

Within the adoption process, the purchase and installation phase proved to be that which was most positively experienced by this study's participants. When satisfied with the purchase and installation process (e.g., the installation was completed in a timely and professional manner), participants had little to voice.

With respect to mixed and negative experiences during the purchase and installation of the solar PV systems, three factors emerged as being prominent. First, the most frequent challenge encountered by 
participants was the length of time required for retailers to install the panels. The installation itself often took less than two days, however, it often took more than a month for the retailers to visit their client's home and to start the installation. Further adding to delays, some installations required minor home renovations for the system to be functional. Second, one participant was discouraged by what he/she perceived to be misinformation provided by the retailer. Upon installation, he/she was left to believe that he/she was connected to the grid and generating electricity that would be compensated by the RESOP; this was not the case. For the first three months of ownership, the participant's solar PV system was neither connected to the grid, nor registered under the RESOP. Third, one participant encountered a number of complications and disappointments with their retailer, including roofing damage and the feeling that he/she had been mislead with regards to the complexity and uncertainty of the adoption process.

It was hypothesized that, because the installation of grid-connected solar PV systems is a relatively new occurrence in Ontario, the negative experiences might be related to when the installations were performed. With respect to retailers who performed installations for more than one participant in this study, the negative experiences occurred during the first installations in all cases. Furthermore, across all participants, each of the relatively negative experiences occurred prior to the implementation of the RESOP. This trend suggests improvement by the retailers, in terms of the installation process, across time.

\subsubsection{Phase II: Connection to the Grid}

The negative experiences identified by study participants when connecting to the electricity grid were found to be related to institutional challenges. These challenges appear to be largely associated with a lack of institutional capacity, and can be explained by two circumstances. First, drawing from interviews with representatives of two LDCs (though not presented in this paper, preliminary interviews were conducted with various stakeholders involved with the RESOP (e.g., LDCs, solar PV system vendors, and CPGs) prior to conducting the primary set of interviews presented here), administration of the RESOP within LDCs is an additional responsibility placed on multiple departments and employees, all of whom already possess other responsibilities. As such, those employees responsible for the execution of the grid connection and billing process simply do not have the time within their daily duties to take care of such tasks in a timely manner.

Second, the RESOP is a relatively new program that provides a novel task for LDCs-the connection of microgenerating RETs to the grid. To do so, technical and engineering considerations and processes must be understood and developed, though minimal instruction or guidance was provided by any party to the LDCs at the outset of the program. As a result, grid connection processes are undergoing their own growing pains, demonstrating an ad hoc learning process by each LDC. Furthermore, because the program is new, it takes more of what already appears to be scarce time for administrators, only serving to further exacerbate the first point.

Ontario is not the first jurisdiction in which challenges have arisen between consumers and their local distribution companies. In Spain, Del Rio and Unruh [9] have identified similarly cumbersome administrative processes and challenges in the grid connection process, noting that "Generators claim that grid access continues to be discriminatory and at unfair fees and directly accuse the grid operator 
and utilities of preventing PV access." Germany [11] has also experienced challenges communicating with its utilities. Painuly [20] suggests that the uptake of RETs by utilities may represent a clash of interests, threatening their dominance and profitability over the energy system.

\subsubsection{Phase III: Completion of a SOC}

Acquisition of the contract is the only direct interaction the consumer has with the Renewable Energy Standard Offer Program, although the requirement for solar PV systems to be grid-tied suggests that interaction with one's LDC is an indirect interaction with the RESOP. The bulk of the interaction with the RESOP is the filling out of the application and its associated documents, submission, and the confirmation of one's contract. To understand the consumer experience with the RESOP, it was first important to understand the extent to which consumers filled out the application. Among the interviewees, there were three approaches in which one may have filled out an application; experiences associated with each application style are described.

The first was to complete the application on one's own. Seven participants chose this path. Participants who completed the RESOP on their own reported the process as being the most challenging. Frustration arose from what was described as a "very tedious, very bureaucratic ... a very challenging process."

Second, some participants filled out the majority of the application, but received assistance in one of two manners. In one case, a retailer provided a guideline document as well as an example of a completed RESOP application for their customers to use. In the second case, consumers contracted their retailer and installer to aid them through the process. In total, seven participants received one of the two forms of assistance when completing the RESOP application process.

Participants in this category found that the efforts of their retailers were, though well-intentioned, inadequate. Negative experiences stemmed from the lack of support provided by the retailer and what they felt to be the cumbersome process required to complete the RESOP application process. Chronologically, a trend emerged, with negative experiences being reported by those participants who were the earliest to adopt, and the most positive experience being the latest.

Thirdly, consumers, other than signing the appropriate documents and providing the personal documentation required by the RESOP, may have contracted another party to complete the entire application for them. Ten participants followed this path. The 'other party' who completed the application for the participant was one of two groups. First, many of the retailers completed the application as part of an installation package for their customer. In the case of smaller retailers, the vender, installer, and RESOP administrative aide were all the same person. In the case of some of the larger retailers, it was the position of someone within that organization to specialize in and complete the SOC.

We have defined the second group as Third Party Administrators (TPA) - independent businesses whose sole responsibility is the completion of the SOC. The sole TPA group contracted amongst interview participants charged a CAD $\$ 300$ fee for completion. Six participants used this TPA.

Every participant, with one exception, who contracted his/her installer or a TPA to complete the SOC process for them, was content with the RESOP administrative process. One participant, despite predominantly positive comments, noted mild frustration with the length of time which it took to 
acquire their contract. It was unclear, however, whether the lengthy processing time was due to a delay in the application by the TPA, or a processing delay by the OPA.

\subsection{Stage 3: Persistence Once Plugged in-The Impact of Word-of-Mouth and Social Influence}

Towards the conclusion of the interview schedule, participants were asked to state whether or not they would recommend either the adoption of a solar PV system or the use of the RESOP to adopt a solar PV system to others. An analysis of participant responses serves two purposes. First, the responses to both questions can function as indicators, gauging the participants' concluding impression of the adoption of a solar PV system and the utilization of the RESOP. Second, by phrasing the question in terms of a recommendation, the analysis of participant responses serves to inform the hypothesis that the experiences of adopters may affect the decision of potential adopters to adopt through social means (i.e., dialogue and a general social perception).

When asked whether they would advise a potential consumer to purchase a solar PV system, 18 of 21 individuals stated that they would recommend such a purchase. The three respondents who responded negatively stated that they would not recommend the adoption of a solar PV system because of the lack of affordability and the emergence of unexpected costs. Table 2 presents sample responses provided by participants.

Table 2. Sample Responses to the Question "Would you recommend purchasing a solar PV system?"

\begin{tabular}{|c|c|}
\hline Recommendation & Sample Responses \\
\hline $\begin{array}{l}\text { Yes, I would } \\
\text { recommend the } \\
\text { purchase of a solar PV } \\
\text { system. }\end{array}$ & $\begin{array}{l}\text { "Would definitely." } \\
\text { "If you really want to do it, then definitely go for it." } \\
\text { "If you've got the money, go for it. This is what you can do to reduce the carbon } \\
\text { footprint of our society." } \\
\text { "I would tell them that we were very satisfied with this and we think it's a good thing to } \\
\text { do both for the environment and as an investment in the future, that it's financially ... } \\
\text { economically viable." } \\
\text { "Yes, definitely. Especially if it's a collaborative initiative." } \\
\text { "If you can afford it and you're interested in doing it ... we'd say yes." } \\
\text { "My advice would certainly be to do it through an initiative happening in their area." }\end{array}$ \\
\hline $\begin{array}{l}\text { No, I would not } \\
\text { recommend the } \\
\text { purchase of a solar PV } \\
\text { system. }\end{array}$ & $\begin{array}{l}\text { "So, we put them up with the idea that we'd get other people going on them too, but now } \\
\text { I can't tell anyone about it. Who are you gonna suggest you get that when ... it's going } \\
\text { to turn people off about doing anything about the environmental problems we have." } \\
\text { "No, but not because of the paperwork, but because of the [additional] cost of it." } \\
\text { "I wish I had nothing to do with this. Why am I doing this?" }\end{array}$ \\
\hline
\end{tabular}

Similarly, participants were asked whether or not they would recommend using the RESOP when purchasing a solar PV system. The reader should bear in mind that one alternative to the use of the RESOP would be participation in the Province of Ontario's Net-Metering Program, wherein electricity produced by one's solar PV system is fed directly into one's home for use, and any surplus electricity is purchased by the LDC at the same rate at which it is sold. Electricity rates in Ontario are typically between CAD\$0.05/kWh and CAD\$0.09/kWh. 
Table 3. Examples of Responses to the Question "Would you recommend using the RESOP?"

\begin{tabular}{ll}
\hline $\begin{array}{l}\text { Recommendation } \\
\text { (frequency) }\end{array}$ & Representative Examples \\
\hline $\begin{array}{l}\text { Yes, I would } \\
\text { recommend } \\
\text { participation in the }\end{array}$ & "This seems to be working very well ... They're paying me 42 cents per \\
RESOP. (15) & "I'd recomment hour." \\
\hline "The RESOP program has a much better return."
\end{tabular}

In comparison, when asked whether or not they would advise a household to utilize the RESOP for solar PV system adoption, only 16 of the 21 participants said they would. Of the five participants who stated they would not recommend the use of the RESOP, three were the same who did not recommend a PV system. In the case of the RESOP, the three participants were frustrated by the unexpected costs associated with the program, such as high meter costs and a monthly administration fee charged by their LDC. The remaining two participants who would not recommended the use of the RESOP did recommend the purchase of a solar PV system. For one of these two participants, the negative recommendation is explained by the following statement:

The solar panels are expensive, but there's no support for doing this at all, in my mind. The utility company's against it ... it's pretty clear. I would never sign up for the Standard Offer Program. Ever. I wouldn't recommend it to anyone. The solar panels I would recommend ... but not the Standard Offer Program. It's too painful. I've been thinking about disconnecting my power completely. I'm frustrated with it. Net-metering would have been a lot simpler; no contracts, no hassle, it would make a lot more sense than this contract. This contract has been a complete failure in my mind.

The second participant's disdain for the RESOP did not come in the acquisition of the SOC, but in the grid connection process required under the RESOP. He/she stated that, in regard to the use of the RESOP, “I wouldn't. [LDC]'s not very interested ... and maybe it's because they're just too big of an organization."

While 16 participants would advise the use of the RESOP, they did so primarily because of the improved payback. If a potential consumer were to probe further into the experience of RESOP participants, they would be exposed to the SOC acquisition experiences encountered by participants, where $21 \%$ of the sample population had negative experiences, and $29 \%$ had a mixed experience, the negative elements of which stemmed primarily from the cumbersome nature of the application itself and delays in the approval process. 
It should also be noted that only 12 participants noted a positive experience in completing the SOC application process, while 16 participants suggested that one should use the RESOP. While experiences may be negative, some element of the RESOP is sufficiently rewarding to merit the advocacy of the program by its current participants. While financial incentives are the obvious explanation, such advocacy might also be explained by the willingness of early adopters to act as "guinea pigs." It was not uncommon for participants to make remarks such as, "Like I say, I was the guinea pig." Participants frequently noted their awareness that in the beginnings of any program or new process, challenges and uncertainties are bound to arise.

\section{Discussion and Policy Recommendations}

As discussed above, economic (e.g., [1,5,10]) and institutional (e.g., [9]) factors have been identified in the literature as two of the leading explanations for the modest levels of solar PV system diffusion. For this reason, it is not surprising that money (i.e., high initial capital cost and lengthy payback periods) and institutional support (CPGs and the RESOP) were found to be of considerable prominence as barriers in the decision-making process of this study's sample participants.

Our results demonstrate that, despite the presence of the most commonly identified barriers (e.g., costs and institutional challenges), sustainability related motivations and the support of CPGs have been sufficiently strong to overcome such barriers. Each of the participants in this study's primary interview sample did, ultimately, adopt a solar PV system. Furthermore, these results echo research that is emerging from Sweden. Tengvard and Palm [20], in studying household motivations for the adoption of residential solar PV systems, found that the most prominent factors for adoption were those related to sustainability. While this research's limited study sample restricts the generalization of its results, Tengvard and Palm's research findings support those present in this research - namely that there exists some set of the broader population who are most concerned with acting out of values for sustainability rather than out of any of the other factors considered.

\subsection{Future Adopters: Population Traits and Awareness}

When interpreting the results of this study, one should be cautious not to underestimate the significance of those barriers mentioned or to overestimate the role of the drivers present with relation to the greater population. As noted, results of this research pertain only to a select group of participants, the early adopters [19]. It has been demonstrated in the literature that such participants share similar character traits to one another, and that future adopter populations will possess different traits $[5,19]$. For example, according to Truffer et al. [21]:

In the case of green electricity, early adopters are likely to be members of the eco-niche. The benefits of switching to green electricity for this group are likely to be the highest, as they perceive environmental action to be necessary, environmental consciousness is part of their identity, and environmental actions may satisfy their need for participation. Given the relatively high value this group receives from choosing green electricity, the benefits of this choice will outweigh the costs at a relatively higher cost level. Spill-over from the 
eco-niche to other consumers, however, is likely to be limited, since the latter have different satisfiers for their needs and perceive the costs of green electricity differently as well.

As such, there is strong reason to assume that future adopters will be less motivated by sustainability-related concerns, and less likely to have the 'staying power' to complete the adoption process in the wake of challenges of cost and administration. This hypothesis is also supported by comments generated throughout the interviews. When discussing the questions that are typically asked by interested parties (e.g., neighbours, relatives), one participant noted that "they ask what the return on investment is." Similarly, another participant noted that "people've been asking the price", and that “anybody who's asked me about it, any of our neighbours or friends who've asked about it, ... the first things without knowing anything about ... is the cost." This was commonplace amongst all interviews.

There is also reason to believe that a lack of awareness may inhibit future solar PV system diffusion. Retailers have noted that many of their interactions with consumers were in the form of information provision and education, as opposed to the selling of the actual systems. If future policy tools are to be successful in facilitating the diffusion of solar PV systems, it is important that the general population becomes more aware and educated about the systems themselves as well as the supporting institutions. While an increased knowledge base will not guarantee improved diffusion rates [22], it will support such an approach.

\subsection{The Introduction of Ontario's Feed-In-Tariff}

In March, 2009, the Ontario Government announced, through its newly developed Green Energy and Green Economy Act, 2009, the creation of a Feed-In Tariff program. The proposed new rate of compensation for the microgenerating solar PV systems will be CAD $\$ 0.802 / \mathrm{kWh}$ [23]. The feed-in tariff will, essentially, replace the RESOP, whether or not the province explicitly planned for this. While this higher rate of pay will certainly provide a greater impetus for the adoption of solar PV systems, many of the challenges and barriers identified within the RESOP may continue to be present in this new system, inhibiting or preventing the adoption of solar PV systems. As a result, as this program, or any one similar to it, moves forward, institutional and administrative challenges should be reduced, if not at least anticipated.

The forthcoming implementation of the Feed-In Tariff will also present an opportunity to further study the relationship between financial incentives and the diffusion of solar PV systems. In particular, a comparison between this study's findings and the increased remuneration provided by the Feed-In Tariff may reveal further insight as to the influence of specific rates of compensation on the rate of solar PV system diffusion. Furthermore, as more people adopt solar PV systems, the type of consumers adopting will eventually transition from the early adopters (the first $15 \%$ of people to adopt) to the early majority (the following 35\% of adopters) [19], and so forth. This transition will present the opportunity to further understand drivers and barriers among a greater proportion of the population. 


\subsection{Recommendations}

One driver and one catalyst have been identified as prominent: sustainability-related concerns (e.g., climate change, the livelihood of future generations) and administrative assistance (e.g., community-based cooperative purchasing groups). A subset of the provincial populace has been found to be willing to purchase a solar PV system primarily out of a concern for sustainability-related issues, while CPGs have been found to support consumers and to not only facilitate the RESOPintegrated adoption process with respect to solar PV systems, but to move consumers from thought to action. Considering that the primary participants of this study chose to adopt a solar PV system and participate in the RESOP, it is apparent that the sum of drivers was of greater significance to their decision-making process than that of the barriers encountered. As such, future strategies developed by policy-makers, retailers, and others involved in the adoption of solar PV systems (e.g., CPGs, manufacturers, etc.), may be improved by promoting the identified drivers, as opposed to, or in conjunction with, the more traditional approach of reducing barriers.

The reduction and elimination of barriers is also necessary to improve the RESOP-integrated adoption process. The two barriers requiring the greatest attention in the case of Ontario are program administration and the high initial capital costs and lengthy payback periods. The administrative requirements and the processes required to meet them must be simplified and clarified. To achieve such improvements, it must be identified whose responsibility it is to develop and improve the administrative process. Once responsibility is attributed, measures for improvement might include a single-window application process that harmonizes both of the OPA and LDC application processes, and the implementation of absolute time limits for the issuance of a SOC and connection to the grid.

Furthermore, despite the CAD $\$ 0.42 / \mathrm{kWh}$ offered by the RESOP, the financial burden continues to be of concern to consumers. If it is the goal of a policy such as the RESOP to increase the diffusion of solar PV systems to a wider population, then an increase in the rate of compensation is recommended. This recommendation may come to fruition with the proposed Feed-In Tariff rate of \$CAD0.802/kWh.

There is reason to believe that monetary and institutional challenges and barriers will become increasingly significant to future adopters; likewise, sustainability-related concerns may decrease as motivators. Bearing in mind this difference between adopter types, any strategy employed should be properly targeted to the population to which it is being applied. This case study has demonstrated that, when addressing the earliest of adopters, emphasis on drivers (e.g., the creation of CPGs or promotion of the contribution to sustainability) may be a more effective approach, whereas the reduction of monetary and institutional barriers may be more effective in garnering the participation of later adopters.

\section{Conclusions}

While the RESOP was designed with the intention of supporting the adoption of rooftop solar PV systems in Ontario, numerous financial and institutional challenges have presented themselves throughout the process since its inception at the end of 2006. Cumbersome administrative processes and hidden costs have provided such negative experiences that, despite the provision of a financial payback, some respondents were deterred from recommending the program. These challenges are 
troublesome with respect to policy design. Certainly, not every policy will be liked by all members of a population; however, it is one thing to say that the RESOP is insufficient in motivating potential consumers to purchase a PV system, and another to note that consumers have had such negative experiences that they are unwilling to recommend the use of the RESOP to future adopters. Given the expectation that financial considerations will weigh more heavily on the decision making of future adopters, and that these future adopters will be less willing to persevere through a cumbersome process, flawed processes and negative experiences may have a detrimental effect on the future adoption of solar PV systems.

The Renewable Energy Standard Offer Program and, in the future the Feed-In Tariff, demonstrate a desire of the province to promote and implement a greater degree of RET adoption within our current energy supply mix. The success of these programs will depend, to varying degrees, upon the institutions set up for their execution and administration and the rate at which generators of "green" electricity are compensated. While some consumers will adopt because of strong sustainability values, moving beyond the early adopter types to the greater population may require a financial incentive that is palatable for potential consumers, and a process that is streamlined and 'user-friendly.' If these requirements can be met, there is hope that residentially-mounted solar PV systems will achieve greater diffusion and be able to contribute an energy supply mix that is sustainable.

\section{Acknowledgements}

This study was completed with support from the Solar Buildings Research Network under the Strategic Network Grants Program of the Natural Sciences and Engineering Research Council of Canada. All research methods utilized were approved by the University of Waterloo's Office of Research Ethics.

\section{References and Notes}

1. Bradford, T. Solar Revolution: The Economic Transformation of the Global Energy Industry; MIT: Cambridge, MA, USA, 2006.

2. Jaccard, M. Sustainable Fossil Fuels: The Unusual Suspect in the Quest for Clean and Enduring Energy; Cambridge University Press: New York, NY, USA, 2005.

3. Monbiot, G. Heat; Anchor Canada: Toronto, ON, Canada, 2006.

4. Renewables Global Status Report: 2009 Update; REN21 Secretariat: Paris, France, 2009.

5. Faiers, A.; Neame, C. Consumer attitudes towards domestic solar power systems. Energ. Policy 2006, 34, 1797-1806.

6. Faiers, A.; Cook, M.; Neame, C. Towards a contemporary approach for understanding consumer behaviour in the context of domestic energy use. Energ. Policy 2007, 35, 4381-4390.

7. Cooke, R.; Cripps, A.; Irwin, A.; Kolokotroni, M. Alternative energy technologies in buildings: stakeholder perceptions. Renew. Energ. 2007, 32, 2320-2333.

8. Boyle, G.; Everett, B.; Ramage, J. Energy Systems and Sustainability: Power for a Sustainable Future; Oxford University Press: Oxford, UK, 2003. 
9. del Rio, P.; Unruh, G. Overcoming the lock-out of renewable energy technologies in Spain: the cases of wind and solar electricity. Renew. Sust. Energ. Rev. 2007, 11, 1498-1513.

10. Jacobsson, S.; Johnson, A. The diffusion of renewable energy technology: an analytical framework and key issues for research. Energ. Policy 2000, 28, 625-640.

11. Jacobsson, S.; Lauber, V. The politics and policy of energy system transformation-explaining the German diffusion of renewable energy technology. Energ. Policy 2006, 34, 256-276.

12. Liberatore, A. Arguments, Assumptions and the Choice of Policy Instruments. In Environmental Policy: In Search of New Instruments; Dente, B., Ed.; Kluwer Academic Publishers: Norwell, MA, USA, 1995; pp. 55-72.

13. Department of Justice Canada. Constituion Acts 1867 to 1982; Canadian Government Publishing: Ottawa, ON, Canada, 2006.

14. Independent Electricity System Operator IESO 2008 Electricity Figures Show Record Levels of Hydroelectric Power; 2009; Available online: http://www. ieso. ca/imoweb/media/md_newsitem. asp?newsID=4458 (accessed on 3 November 2009).

15. Rowlands, I.H. The development of renewable electricity policy in the Province of Ontario: the influence of ideas and timing. Rev. Policy Res. 2007, 24, 185-207.

16. Ontario Ministry of Energy and Infrastructure Net Metering; 2008; Available online: http://www.mei.gov.on.ca/english/energy/renewable/?page=net-metering (accessed on 3 November 2009).

17. Standard Offer Prgoram -Renewable Energy: For Small Electricity Generators-An Introductory Guide. Ontario Power Authority: Toronto, ON, Canada, 2006.

18. A Progress Report on Renewable Energy Standard Offer Program: December 2008; Ontario Power Authority: Toronto, ON, Canada, 2008.

19. Rogers, E.M. Diffusion of Innovations, 5th ed.; Free Press: New York, NY, USA, 2003.

20. Tengvard, M.; Palm, J. Small-Scale Production of Electricity: Part of Sustainable Living for Households. In Proceedings of the ECEEE Summer Study 2009 Conference, Linkoping, Sweden, June 1-6, 2009.

21. Fuchs, D.A.; Arentsen, M. Green electricity in the market place: the policy challenge. Energ. Policy 2002, 30, 525-538.

22. McKenzie-Mohr, D. Promoting sustainable behaviour: an introduction to community-based social marketing. J. Soc. Issues 2000, 56, 543-554.

23. Ontario Power Authority FIT Price Schedule-Draft March 13, 2009; Available online: http://www. powerauthority. on. ca/fit/Storage/29/10116_FIT_Price_Schedule_Draft_March_13_ 2009. pdf (accessed on 7 September 2009).

(C) 2010 by the authors; licensee Molecular Diversity Preservation International, Basel, Switzerland. This article is an open-access article distributed under the terms and conditions of the Creative Commons Attribution license (http://creativecommons.org/licenses/by/3.0/). 